\title{
Effect on Refractive Outcomes after Cataract Surgery of Intraocular Lens Constant Personalization Using the Haigis Formula
}

\author{
Sofia Charalampidou \\ Waterford Institute of Technology \\ Lorraine Cassidy \\ Royal Victoria Eye and Ear Hospital, Dublin \\ Eugene $\mathrm{Ng}$ \\ Cork University Hospital
}

See next page for additional authors

Follow this and additional works at: https://arrow.tudublin.ie/otpomart

Part of the Optometry Commons

\section{Recommended Citation \\ Charalampidou, S.,Cassidy, L., Ng, E., Loughman, J., Nolan, J., Stack, J. Beatty, S.: Effect on Refractive Outcomes after Cataract Surgery of Intraocular Lens Constant Personalization Using the Haigis Formula.J ournal of Cataract \& Refractive Surgery. Vol. 36, Issue 7, Pages 1081-1089. July 2010. doi:10.1016/ j.jcrs.2009.12.050}

This Article is brought to you for free and open access by ARROW@TU Dublin. It has been accepted for inclusion in Articles by an authorized administrator of ARROW@TU Dublin. For more information, please contact arrow.admin@tudublin.ie, aisling.coyne@tudublin.ie, gerard.connolly@tudublin.ie.

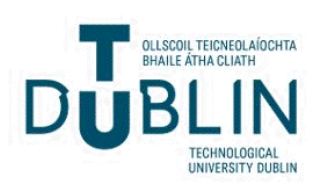




\section{Authors}

Sofia Charalampidou, Lorraine Cassidy, Eugene Ng, James Loughman, John Nolan, Jim Stack, and Stephen Beatty

This article is available at ARROW@TU Dublin: https://arrow.tudublin.ie/otpomart/12 
Optimized versus Personalized Lens Constants

\section{The impact of lens constant personalization on}

\section{refractive outcomes following cataract surgery using}

\section{the Haigis formula}

Dr. Sofia Charalampidou, MRCPI, MRCOphth ${ }^{1}$

Professor Lorraine Cassidy, FRCOphth ${ }^{2,3}$

Dr. Eugene Ng, MRCOphth ${ }^{4}$

Mr. James Loughman, $\mathrm{PhD}^{5,6}$

Dr. John Nolan, $\mathrm{PhD}^{5}$

Mr. Jim Stack, $P h D^{5}$

Mr. Stephen Beatty, MD, FRCOphth ${ }^{1,5}$

1. Institute of Eye Surgery and Institute of Vision Research, Whitfield Clinic, Butlerstown North, Cork Road, Waterford, Ireland

2. Royal Victoria Eye and Ear Hospital, Adelaide Road, Dublin, Ireland

3. Department of Ophthalmology, Trinity College, University of Dublin

4. Ophthalmology Department, Cork University Hospital, Cork, Ireland

5. Macular Pigment Research Group, Waterford Institute of Technology, Cork Road, Waterford, Ireland

6. School of Optometry, Dublin Institute of Technology, Dublin, Ireland

Corresponding Author: Dr. Sofia Charalampidou

Address: Institute of Eye Surgery, Whitfield Clinic, Cork Road, Waterford

Email: sonia.sofia1@gmail.com

No author has a financial or proprietary interest in any material or method mentioned in this article. 


\section{Abstract}

Purpose: To collate views on, and extent of practice of, lens constant personalization among consultant ophthalmic surgeons in the UK and Ireland and to investigate, describe and quantify the effect of personalization of Haigis lens constants, for a given surgeon/intraocular lens (IOL) combination, on refractive outcomes following cataract surgery

Setting: Institute of Eye Surgery and Institute of Vision Research, Whitfield Clinic, Butlerstown North, Cork Road, Waterford, Ireland.

Methods: A postal survey of all consultant ophthalmic surgeons in the UK and Ireland, regarding the practice of lens constant personalization, was carried out. Also, mean error (ME) of prediction and mean absolute error (MAE) were calculated for a single-surgeon (SB) series of eyes after biometry by partial coherence interferometry $(\mathrm{PCl})$ with the $\mathrm{IOL}$ Master and phacoemulsification cataract surgery, where the IOL prediction was based on the Haigis formula and optimized lens constants derived from pooled data from the ULIB (User Group for Laser Interference Biometry) website. Personalization of Haigis lens constants to the same operating surgeon was then performed. An ME of prediction and an MAE using the personalized lens constants was then calculated for the same series of eyes which had been operated upon using the Haigis optimized (but not personalized) lens constants, thereby allowing us to investigate and quantify the maximum realizable refractive benefits (if any) of personalization. 
Optimized versus Personalized Lens Constants

\section{Results:}

\section{Survey:}

The survey response rate was $56 \%$. One hundred and ten (21.7\%) of the 506 consultant ophthalmic surgeons in the UK and Ireland who answered the questionnaire did formally personalize their lens constants by a recognized and validated method. The most common reason for non-personalization of lens constants was the use of optimized lens constants derived from pooled data.

\section{Refractive results:}

The ME of prediction and the MAE with Haigis optimized lens constants were $-0.09 D( \pm$ $0.48)$ and $0.38 \mathrm{D}( \pm 0.31)$, respectively, and this compares with $+0.01 \mathrm{D}( \pm 0.47)$ and 0.36 D (+/- 0.30), respectively, for personalized lens constants. There was no statistically significant difference between personalization and optimization of Haigis lens constants in terms of the AE (paired t-test: $p>0.05$ ) or in terms of the proportion of eyes within \pm 1.00 $\mathrm{D}$, within $\pm 0.50 \mathrm{D}$ or within $\pm 0.25 \mathrm{D}$ of target postoperative refraction in all eyes, short eyes $(A L<22 \mathrm{~mm}, \mathrm{n}=19)$, average eyes $(A L \geq 22 \mathrm{~mm}$ and $A L<24.5 \mathrm{~mm}, \mathrm{n}=149)$ or long eyes ( $A L>24.5 \mathrm{~mm}, \mathrm{n}=46)$ (McNemar's test: $p>0.05$ for all). Ten eyes had a smaller AE by $0.3 \mathrm{D}$ or more in association with personalized lens constants when compared with optimized lens constants, and all of these eyes were short. However, no eyes exhibited a smaller $\mathrm{AE}$ by $0.5 \mathrm{D}$ or more in association with personalized lens constants when compared with optimized lens constants.

Conclusion: Personalized Haigis lens constants showed marginal, but statistically nonsignificant, refractive advantages over optimized Haigis lens constants, but only in short eyes. However, clinically meaningful refractive advantages of personalized Haigis lens constants were not demonstrated, and would be restricted to very high volume cataract 
Optimized versus Personalized Lens Constants

surgeons, and then only as long as they continue to use the same model of IOL that was

1 employed in the process of personalization. 
Optimized versus Personalized Lens Constants

\section{Introduction}

Modern cataract surgery may be regarded as a refractive procedure, $(1,2)$ with patients having high expectations of their cataract surgeon and low tolerance for less than perfect results. $(1,3)$ Indeed, the most common cause for litigation arising from cataract surgery is the implantation of an intraocular lens (IOL) of inappropriate power. (1)

Refractive outcomes following cataract surgery have improved dramatically over the last few years. The percentage of operated eyes with a postoperative refraction within $\pm 1 \mathrm{D}$ of the target refraction has increased from $65 \%$ (4) to over $95 \%$, and even $100 \%$ in certain series. (5-9) Indeed, a recent multicenter prospective electronic audit of over 4,000 cataract operations, with data collected in 3 cycles over a 3-year period, suggested that $85 \%$ of postoperative refractive results lying within $\pm 1 \mathrm{D}$, and $55 \%$ of postoperative refractive results lying within $\pm 0.5 \mathrm{D}$, of target postoperative refraction, should represent the current and minimally acceptable standard for the purposes of clinical audit. (9) The authors also concluded that continuous customization/optimization of IOL $A$ constants is important in order to achieve the proposed benchmark standards in postoperative cataract refractive outcomes.

This improvement in refractive outcomes following cataract surgery is attributable to the fact that variables used in the prediction of refractive outcomes following cataract surgery can now be validly and reliably measured prior to surgical intervention, by either immersion ultrasound biometry or by optical coherence biometry (OCB). $(2,10-12)$ In other words, the impact of the major contributors to refractive error following cataract surgery has been substantially reduced by improvements in measures of biometric parameters 
Optimized versus Personalized Lens Constants

Further, personalization of lens constants to the individual surgeon has been advocated by

many authors for almost 30 years and it is believed to represent an important step if yet further improvements in refractive outcomes following cataract surgery are to be realized. (2, 13-17), (http://www.augenklinik.uni-wuerzburg.de/ulib/cl.htm. Accessed on the 18/12/2009), and (http://doctor-hill.com/zeiss iolmaster/haigis formula.htm. Accessed on the $18 / 12 / 2009)$.

Personalization of lens constants can be carried out for all currently used formulas, including $3^{\text {rd }}$ generation 2-variable formulas (Hoffer Q(15), Holladay 1(17) and SRK/T(18)), 3-variable formulas (Haigis(19)) and 7-variable formulas (Holladay 2).

The IOL power prediction curve of the $3^{\text {rd }}$ generation 2-variable formulas is mostly fixed and is moved up or down depending on the IOL constant (the larger the IOL constant, the more IOL power each formula will recommend for the same set of biometric measurements; and the smaller the IOL constant, the less IOL power the same formula will recommend for the same set of biometric measurements). Those formulas do not take into account the individual geometry of each lens model. They also assume that anterior chamber dimensions are related to AL. In other words, they assume that short eyes have shallower anterior chambers and that long eyes have deeper anterior chambers. But we know this to be untrue, and that $80 \%$ of short eyes have large crystalline lenses, but normal anterior chamber anatomy in the pseudophakic state (http://doctor-hill.com/iolmain/formulas.htm. Accessed on the 18/12/2009). However, another erroneous assumption made is that steep corneas have deep anterior chambers while flatter corneas have shallower anterior chambers. 
The Haigis formula is different from the 2-variable formulas. It uses three constants (a0, a1

and a2) to set both the position and the shape of a power prediction curve. The a0 constant moves the power prediction curve up, or down, the a1 constant is tied to the measured anterior chamber depth and the a2 constant is tied to the measured axial length. The a0, a1 and a2 constants are derived by multi-variable regression analysis from a large sample of surgeons and IOL-specific outcomes for a wide range of axial lengths and anterior chamber depths and they are published in the ULIB website (http://www.augenklinik.uni-wuerzburg.de/ulib/cl.htm. Accessed on the 18/12/2009) These "optimized" lens constants are based on pooled data from multiple surgeons. Similarly, an individual surgeon can submit their IOL-specific outcomes to Dr. Haigis and acquire a set of a0, a1 and a2 constants that are specific to that particular surgeon/IOL combination, thereby "personalizing" these constants.

To the authors' knowledge, the extent of the practice of lens constant personalization is not known. We carried out an anonymous survey of cataract surgeons in the United Kingdom and Republic of Ireland, in order to ascertain the proportion of surgeons that incorporate optimized and/or personalized lens constants into their practice, the methods used to do so and the reasons some surgeons choose not to. In the survey and in this paper, the term "optimization" was used for lens constants derived from multi-surgeon pooled data and the term "personalization" for lens constants derived from single-surgeon data.

Also, we have designed, executed and report a study that analyzes the refractive impact of personalizing lens constants, where the ME of prediction and MAE generated using personalized Haigis lens constants and non-personalized (but optimized) Haigis lens 
constants were compared for a given series of eyes operated upon by a single surgeon, using a single model of IOL.

\title{
Materials and Methods
}

\author{
Survey
}

We carried out a postal survey of all consultant ophthalmologists in the United Kingdom and Republic of Ireland. In June 2009, we mailed questionnaires to 943 names on a database of members held by the Royal College of Ophthalmologists, and to 65 names on a database of members held by the Irish College of Ophthalmologists. The mailing comprised a two-page anonymous questionnaire, with a covering letter and a stamped addressed envelope for return.

Ophthalmologists were asked a series of questions about lens constant optimization and personalization in relation to their practice of cataract surgery. Specifically, they were asked whether they personally perform cataract surgery (if the answer was no, they were not required to answer any more questions); whether they use published optimized lens constants (derived from pooled data) from the ULIB (User Group for Laser Interference Biometry) website; whether they personalize their lens constants by analyzing their own postoperative refractive data; and if so, which method of lens constant personalization they employed; and finally, if they do opt not to personalize their lens constants, to offer reasons for this decision. 
Optimized versus Personalized Lens Constants

The completed questionnaires were returned to the lead investigator, and the responses

were manually entered into a customized database for analysis.

\section{Personalized Haigis versus Optimized Haigis Lens constants}

Preoperative, intraoperative and postoperative data were prospectively collected from 577 consecutive cases of phacoemulsification cataract surgery, performed by a single surgeon (SB). Exclusion criteria included: any preoperative visually consequential ocular comorbidity; any previous intraocular surgery; any intraoperative complication; use of a posterior chamber IOL other than the AMO Tecnis ZA9003 ${ }^{\circledR} \mathrm{IOL}$; insufficient biometry data; inability to perform OCB; insufficient postoperative refractive data; and postoperative corrected distance visual acuity (CDVA) of worse than 0.5 at subjective refraction performed 6 to 8 weeks following surgery by the patient's optometrist. Following implementation of these exclusion criteria, 248 consecutive cases were deemed eligible for analysis.

\section{Preoperative data}

\section{Ocular Biometry}

Partial coherence interferometry $(\mathrm{PCl})$ was performed with the IOL Master ${ }^{\circledR}$ Version $\mathrm{V}$ (Carl Zeiss Meditec AG, Jena, Germany). A single experienced operator took all measurements using standard technique. Where any doubt existed, readings were repeated, and only accepted where reproducibility of the readings was demonstrable. Measurement of the following parameters was carried out: axial length, keratometry, 
Optimized versus Personalized Lens Constants

anterior chamber depth and white-to-white. The Haigis formula was used in each case, to recommend the power of IOL to be implanted to achieve the closest minus postoperative refraction to emmetropia. The Haigis $\mathrm{a} 0$, a1 and a2 constants for the AMO Tecnis ZA $9003^{\circledR}$ were downloaded from the ULIB website onto the software of the IOL Master ${ }^{\circledR}$ (optimized lens constants: $a 0=-0.879$, a1=0.252, a2 $=0.220$; based on $n=421$ sets of postoperative refractive data). In cases where $\mathrm{PCl}$ was unattainable, immersion ultrasound biometry was performed instead, and those cases were excluded from the study.

\title{
Intraoperative data
}

\begin{abstract}
All procedures were performed under topical anesthesia by a single consultant ophthalmic surgeon (SB), using standard surgical technique. A clear corneal incision was constructed superiorly.
\end{abstract}

An AMO Tecnis ZA9003® intraocular lens was placed in the capsular bag. On occasion, a $10 / 0$ nylon suture was placed in the corneal incision, when the surgeon was not satisfied with wound integrity following stromal hydration.

\section{Postoperative data}

Patients were reviewed two weeks following surgery, consistent with the unit's postoperative protocol.(20) Uncorrected distance visual acuity (UDVA) and CDVA were recorded at this visit, and anything untoward reported by the patient was investigated by the ophthalmologist. Where a corneal suture was present, it was removed. 
Optimized versus Personalized Lens Constants

Following the two-week review, refraction for fresh spectacle correction was arranged with

a local optometrist, and the results of that were forwarded to the practice. All reported refractions relate to an examination undertaken at least 6 weeks following the surgery (and therefore considered stable) (http://www.augenklinik.uni-wuerzburg.de/ulib/cl.htm. Accessed on the 18/12/2009), and at least 4 weeks following removal of the corneal suture (if present).

\section{Personalization of lens constants}

Data from the 248 eligible cases were entered into the Excel spreadsheet zeiss-d2.xls on the ULIB website (http://www.augenklinik.uni-wuerzburg.de/ulib/cl.htm. Accessed on the 18/12/2009), Data necessary for each subject for the purposes of the spreadsheet included: unique patient identification number (ID); preoperative axial length (AL) in millimeters $(\mathrm{mm})$ as measured by the $\mathrm{IOL}$ Master; preoperative anterior chamber depth (ACD) in $\mathrm{mm}$ as measured by the IOL Master; preoperative corneal radii $\mathrm{K} 1$ and $\mathrm{K} 2$ in $\mathrm{mm}$ as measured by the IOL Master; power of implanted IOL in dioptres (D); spherical component of stable postoperative refraction in D; and cylindrical component of stable postoperative refraction in D. Additional information requested on the spreadsheet included the surgeon's name or ID; the manufacturer and type of IOL; serial number of the IOLMaster; and the method of determining stable refractive status.

The completed spreadsheet was emailed directly to w.haigis@augenklinik.uniwuerzburg.de. Three-variable regression analysis was performed, calculating the personalized a0, a1 and a2 constants for the AMO Tecnis ZA9003 ${ }^{\circledR}$ intraocular lens for the given surgeon (SB). The outcomes of the analysis were subsequently posted to ULIB web 
Optimized versus Personalized Lens Constants

site, as per the agreement outlined on the website (http://www.augenklinik.uni-

\section{Statistics}

An error of prediction was derived for each eye to show the tendency of prediction performance by the Haigis formula in combination with optimized (but not personalized) lens constants. The error of prediction is the actual postoperative spherical equivalent (SE) minus the target postoperative SE, and tells us how close the actual postoperative refraction of each eye is to the target postoperative refraction. The sign of the error of prediction denotes the direction of the departure from the target. In other words, a negative error of prediction value means that the subject ended up with a more myopic refraction than intended, while a positive error of prediction value means that the subject ended up with a more hypermetropic refraction than intended. An absolute error (AE) was also derived for each eye. This is the absolute value of the error of prediction of each eye, and denotes the distance of the refraction from zero, without taking into account whether the departure from zero was in the myopic or hypermetropic direction.

The personalized a0, a1 and a2 constants for surgeon SB and the AMO Tecnis ZA9003 ${ }^{\circledR}$ intraocular lens were subsequently entered into the software of the IOL Master® Version V. The IOL Master calculated, for 219 out of 248 eyes in our series (the biometry of 29 eyes had been removed from the IOL Master and was not available for recalculation), and using the newly personalized lens constants and the Haigis formula, the putative postoperative target SE for the IOL power that had actually been implanted. In so doing, we were able to compare the actual error of prediction using optimized lens constants 
Optimized versus Personalized Lens Constants

(already calculated) with a putative error of prediction using personalized lens constants (the latter calculated as the difference between the actual postoperative SE minus the target postoperative SE for the IOL actually implanted, but derived using the personalized Haigis lens constants). We also derived a putative AE for this series of eyes and our personalized Haigis lens constants. In this way, and in the context of each operated eye acting as its own control, we were able to investigate, describe and quantify the maximum realizable refractive benefits of personalization of lens constants for a given surgeon in terms of the error of prediction and AE.

Refractive outcomes using personalized Haigis lens constants and non-personalized (but optimized) Haigis lens constants were compared in terms of the MAE (Student's paired ttest) for the series of eyes as a whole and also for 3 subgroups: short eyes $(A L<22 \mathrm{~mm}$, $n=21)$, average eyes $(A L \geq 22 \mathrm{~mm}$ and $A L<24.5 \mathrm{~mm}, \mathrm{n}=180)$ and long eyes $(A L>24.5 \mathrm{~mm}$, $n=47)$. Performance of each group of lens constants across AL subgroups was also examined (ANOVA).

Also, the proportion of operated eyes achieving an error of prediction within $\pm 0.25 \mathrm{D}, \pm$ $0.50 \mathrm{D}$ and $\pm 1.00 \mathrm{D}$ was calculated for the whole series and for each of the 3 subgroups, and in each case, agreement between personalized and optimized lens constants was investigated (McNemar's test). Agreement between the AE for personalized Haigis and non-personalized (but optimized) Haigis lens constants was also represented using Bland Altman plots, for the whole series of eyes and for each of the 3 subgroups. Of note, for statistical purposes, eyes were analyzed independently in patients who underwent sequential bilateral cataract surgery during the study period, as it has been shown that the correlation between fellow eyes is weak when reporting refractive outcome following 
cataract surgery.(21) The software package PASW Statistics18.0 and statistical programming language $\mathrm{R}$ (www.R-project.org) were used for the statistical analysis.

\section{Results}

\section{Survey}

Questionnaire return

We received 561 completed responses out of 1008 questionnaires posted (55.7\% response rate). A total of $9.8 \%(55 / 561)$ of respondents did not personally perform cataract surgery, and their responses were therefore excluded from further analysis, while $90.2 \%$ (506/561) did personally perform cataract surgery.

\section{Use of published optimized lens constants (derived from pooled data)}

Of the 506 cataract surgeons who responded to the questionnaire, $39.7 \%(201 / 506)$ reported using published optimized lens constants (derived from pooled data) from the ULIB website. A total of $48 \%(243 / 506)$ of cataract surgeons reported not using published optimized lens constants, $11.5 \%(58 / 506)$ of cataract surgeons did not know whether they were using published optimized lens constants and 4 cataract surgeons $(0.8 \%)$ did not answer the question. 


\section{Personalization of lens constants}

Over $78 \%$ of cataract surgeons $(396 / 506,78.3 \%)$ reported that they did not formally personalize their lens constants using a validated and recognized technique, while nearly $22 \%(110 / 506,21.7 \%)$ reported that they did. Methods of personalization are given in Table 1.

Reasons for not personalizing lens constants

Of the 308 respondents who reported that they did not personalize their lens constants by any means (even informal methods), 40.3\% (124/308) used optimized lens constants from the ULIB website, while $45.1 \%$ (139/308) used neither optimized nor personalized lens constants, $14 \%$ (43/308) didn't know whether they use optimized lens constants or not; and $0.6 \%(2 / 308)$ of respondents did not answer the question.

Of the 124 respondents that used ULIB-derived (but not personalized) lens constants, $41.2 \%(61 / 124)$ felt that their postoperative refractive results were satisfactory using the website optimized lens constants and therefore did not feel the need to personalize them, while $18.5 \%$ (23/124) felt there was no good evidence in support of personalization. Eight percent $(10 / 124)$ of respondents did not explain why they did not personalize, $6.5 \%(8 / 124)$ are currently preparing to start personalizing, $7.3 \%(9 / 124)$ worked in a department were the biometry machine is used by more than one surgeon, making personalization of lens constants logistically difficult, $6.5 \%(8 / 124)$ did not have the time to undertake such a process, $5.6 \%(7 / 124)$ lacked the postoperative refractive results, $2.4 \%(3 / 124)$ performed 
Optimized versus Personalized Lens Constants

low volume surgery and 1 respondent did not know what the term personalization of lens constants meant.

\section{Postoperative refractive results}

Patients were excluded because of lack of postoperative refractive data in $19.9 \%$ $(115 / 577)$ of cases, because of lack of biometric data in $19.4 \%(112 / 577)$ of cases, because of postoperative CDVA $>0.5$ in $11.6 \%(67 / 577)$ of cases, because of an intraoperative complication in $1.2 \%(7 / 577)$ of cases, because of lack of PCl biometry in $0.5 \%(3 / 577)$ of cases and because of the use of a lens other than the Tecnis $Z$ A $9003^{\circledR}$ in $4.3 \%(25 / 577)$ of cases, leaving 248 consecutive cataract procedures of 195 patients for inclusion in the study. The mean age was 71 years \pm 9.3 , the female to male ratio was $122: 73$ (63 \% female) and the right eye to left eye ratio was 120:128.

The Haigis optimized (but non-personalized) a0, a1 and a2 constants for the AMO Tecnis ZA9003 ${ }^{\circledR}$ used in this study were: a0 $=-0.879$, a1 $=0.252$, a2 $=0.220$ (based on $\mathrm{n}=421$ sets of postoperative refractive data and taken from the ULIB website). The mean postoperative SE derived using the optimized (but non-personalized) Haigis lens constants was $-0.24 \mathrm{D} \pm 0.5 \mathrm{D}$ (range: -2.50 to $+0.88 \mathrm{D}$ ). The mean logMAR CDVA postoperatively was $0.06 \pm 0.12$. The postoperative refractive results from this single-surgeon series were used to personalize the above Haigis lens constants.

The Haigis personalized a0, a1 and a2 constants for the AMO Tecnis ZA9003 ${ }^{\circledR}$ derived from our dataset were: $\mathrm{a} 0=-2.341, \mathrm{a} 1=0.278$, a2 $=0.276$ (based on $\mathrm{n}=248$ sets of postoperative refractive data emailed to Dr. Haigis). 
The ME of prediction and MAE with Haigis optimized lens constants and with Haigis

personalized lens constants, and percentage of eyes with an error of prediction of \pm 1.00 $D, \pm 0.50 D$ and $\pm 0.25 D$ in all eyes $(n=214)$, short eyes $(n=19)$, average eyes $(n=149)$ and long eyes $(n=46)$ are given in Table 2 . There was no statistically significant difference between personalized lens constants versus optimized lens constants in terms of $A E$ in any of the subgroups (ANOVA 1-way: $p=0.275$ ), as illustrated by boxplots (Figure 1) and Bland-Altman plots (Figure 3). The Bland-Altman plots demonstrate that for all eyes, average eyes and long eyes (Figure $2 A, 2 C$ and $2 D$ ), the variance is stable, and positive and negative differences occur randomly as we move across from left to right (i.e. with increasing MAE). For short eyes, the Bland-Altman plot (Figure 2B) suggests that increasing MAE ( 0.7 or above) is associated with a mean difference in $\mathrm{AE}$ that is always negative in association with personalized lens constants. However, this group has only 19 eyes and only 4 of those have an MAE of 0.7 or above.

The cumulative percentage of operated eyes (y axis) that achieved less than or equal to a given error of prediction is illustrated in Figure 3 , in all eyes $(A)$, short eyes $(B)$, average eyes $(C)$ and long eyes $(D)$; it is clearly demonstrated that the performance of optimized and personalized lens constants was very similar, except in the case of short eyes, where the use of personalized lens constants was associated with a slightly higher proportion of eyes achieving a postoperative refraction within $\pm 1.00 \mathrm{D}$ of target postoperative refraction when compared with optimized lens constants.

Ten eyes in the entire series had a smaller AE by $0.3 \mathrm{D}$ or more in association with personalized Haigis lens constants when compared with optimized Haigis lens constants, and all of these eyes were short, but no eyes in the series exhibited a smaller AE by $0.5 \mathrm{D}$ or more in association with personalized Haigis lens constants when compared with 
Optimized versus Personalized Lens Constants

optimized Haigis lens constants. However, and in contrast, only four eyes had a smaller

$\mathrm{AE}$ by $0.3 \mathrm{D}$ or more in association with optimized Haigis lens constants when compared with personalized Haigis lens constants, and again, all of these eyes were short.

\section{Discussion}

The aim of this study was two-fold. Firstly, we carried out a survey of cataract surgeons in the United Kingdom and Republic of Ireland, in order to ascertain the attitudes towards, and extent of, the practice of lens constant personalization. Secondly, we designed and executed a study that investigated and quantified the maximum realizable refractive benefits of personalized Haigis lens constants over optimized Haigis lens constants. We achieved the latter by comparing the error of prediction and AE from a single-surgeon series of eyes in which optimized Haigis lens constants were used for the prediction of IOL power in order to achieve emmetropia with an identical theoretical series of eyes where personalized Haigis lens constants were used. The design of the study (comparing a series of eyes with an identical theoretical series) ensured that the maximum realizable refractive benefits of personalized Haigis lens constants could be investigated and quantified.

In addition to the core data retrieved from the anonymous survey, it was apparent that there is considerable confusion regarding terminology on the subject of lens constant manipulation, with no universally accepted system of nomenclature. The terms optimization, customization, personalization and individualization have all been used, sometimes interchangeably, to refer to different aspects of lens constant manipulation. (4, 9, 22, 23), (http://www.augenklinik.uni-wuerzburg.de/ulib/cl.htm. Accessed on the 
18/12/2009) and (http://doctor-hill.com/zeiss iolmaster/haigis formula.htm. Accessed on

the 18/12/2009). We are proposing a system of nomenclature which is clear and unambiguous and which helps the cataract surgeon to understand the principles behind the methods described. We propose using the term "optimization" when lens constants are derived from multi-surgeon pooled postoperative refractive data (either published pooled data, or unpublished pooled data within a department) and the term "personalization" when lens constants are derived from a single surgeon's postoperative refractive data.

Lens constant personalization was performed by less than $22 \%$ of respondents to the survey. When the remaining respondents were asked why they opt not to personalize, the single most frequently cited reason was that they choose to use published optimized lens constants rather than personalized lens constants.

The logistical difficulties inherent in lens constant personalization were also illustrated in this study, and are reflected in the answers to the survey as to why ophthalmic surgeons opt not to personalize (e. g. lack of time, use of the biometry machine by more than one surgeon making isolation of single-surgeon data difficult, inadequate number of cases due to low volume surgery, lack of postoperative refractive data, etc.) and by our experience in terms of collating appropriate datasets for personalization. For example, we had to prospectively recruit 577 consecutive cases of phacoemulsification cataract surgery by a single surgeon, a process that took some 12 months even in a high-volume cataract surgery practice, in order to yield 248 datasets with which to personalize our lens constants because of the stringent inclusion criteria required for a valid process of lens constant personalization. Furthermore, given that rapid advances in $\mathrm{IOL}$ technology in the modern era mean that a typical practice is likely to adopt a new model of $\mathrm{IOL}$ at relatively 
Optimized versus Personalized Lens Constants

frequent intervals (in our practice, approximately every 24 months), the refractive benefits of using personalized lens constants (if any) will be short-lived.

Most authors measure refractive outcomes in terms of the proportion of eyes achieving an error of prediction within $\pm 1.00 \mathrm{D}$ and/or within $\pm 0.5 \mathrm{D}$ of target. Indeed, current proposed benchmark standards for postoperative cataract refractive outcomes are reported in this way. $(9,15,24-26)$ In this study, optimized Haigis lens constants achieved postoperative refractive outcomes which compare favorably with currently proposed benchmark standards, with $96 \%$ of eyes and $73 \%$ of eyes achieving an error of prediction within \pm $1.00 \mathrm{D}$ and $\pm 0.5 \mathrm{D}$ of target, respectively, with no statistically significant difference between optimized Haigis and personalized Haigis lens constants being demonstrable in terms of such outcomes.

Unprompted comments included in replies to the survey indicate that many remain unconvinced of the advantages of personalized lens constants over published optimized lens constants. In our investigation into the benefits of personalized Haigis lens constants, we found that the MAE achieved with optimized lens constants in a single-surgeon series of eyes was not statistically different to the MAE achieved with personalized lens constants. This finding held true regardless of eye axial length. Also, there was excellent agreement between the AEs achieved with personalized and optimized lens constants and, again, this was not affected by axial length. Notably, only 10 eyes (all short) benefited from a smaller $\mathrm{AE}$ by $0.3 \mathrm{D}$ or more in association with personalized lens constants when compared with optimized lens constants, and in no case did personalization of lens constants confer a refractive benefit (in terms of $\mathrm{AE}$ ) of $0.5 \mathrm{D}$ or more. Given that the vast majority of IOLs come in increments of $0.5 \mathrm{D}$, it is therefore difficult to argue strongly in favor of personalization of Haigis lens constants. However, it should be borne in mind that 
Optimized versus Personalized Lens Constants

the validity of lens constants, whether personalized or optimized, will relate to the size of

the dataset from which the lens constants have been derived. In this study, databases of 421 eyes and 248 eyes were used to derive the optimized and personalized Haigis lens constants, respectively.

\section{Conclusion}

Personalization of Haigis lens constants results in a marginal, but statistically nonsignificant, improvement in refractive outcomes following cataract surgery, and only for short eyes. In real terms, however, 577 consecutive datasets by a single cataract surgeon were required to meet inclusion criteria for the process of personalization, resulting in 248 datasets deemed eligible for the process, and ultimately resulting in only 10 eyes with an AE more favorable using personalized lens constants versus optimized lens constants by a degree of $0.30 \mathrm{D}$ or more, and no eyes exhibiting a refractive advantage of $0.5 \mathrm{D}$ or greater. Although continuous audit is an essential component of modern cataract surgery, the refractive benefits of using personalized Haigis lens constants over optimized Haigis lens constants are unlikely to be clinically meaningful unless the surgeon in question is performing a very high volume of cases annually, and even then only as long as that surgeon continues to use the same model of IOL that was employed in the process of personalization. 


\section{References}

1. Chu RY. Cataract Surgery: New Options, New Challenges. Review of Ophthalmology. 2006.

2. Riederle F, Buchwald HJ, Preissinger C, Lang GK. [Refractive aspects of modern cataract surgery]. Klin Monatsbl Augenheilkd. 2006 Dec;223(12):943-51.

3. Dell SJ. Screening and Evaluating Presbyopic Patients. Cataract \& Refractive Surgery Today. 2007 March:81-2.

4. Madge SN, Khong CH, Lamont M, Bansal A, Antcliff RJ. Optimization of biometry for intraocular lens implantation using the Zeiss IOLMaster. Acta Ophthalmol Scand. 2005 Oct;83(5):436-8.

5. Packer M, Fine IH, Hoffman RS, Coffman PG, Brown LK. Immersion A-scan compared with partial coherence interferometry: outcomes analysis. J Cataract Refract Surg. 2002 Feb;28(2):239-42.

6. Olsen T. Improved accuracy of intraocular lens power calculation with the Zeiss IOLMaster. Acta Ophthalmol Scand. 2007 Feb;85(1):84-7.

7. Eleftheriadis $\mathrm{H}$. IOLMaster biometry: refractive results of 100 consecutive cases. $\mathrm{Br}$ J Ophthalmol. 2003 Aug;87(8):960-3.

8. Percival SP, Vyas AV, Setty SS, Manvikar S. The influence of implant design on accuracy of postoperative refraction. Eye. 2002 May;16(3):309-15.

9. Gale RP, Saldana M, Johnston RL, Zuberbuhler B, McKibbin M. Benchmark standards for refractive outcomes after NHS cataract surgery. Eye. 2009 Jan;23(1):14952.

10. Haigis W, Lege B, Miller N, Schneider B. Comparison of immersion ultrasound biometry and partial coherence interferometry for intraocular lens calculation according to Haigis. Graefes Arch Clin Exp Ophthalmol. 2000 Sep;238(9):765-73.

11. Haigis W. Optical Biometry Using Partial Coherence Interferometry. In: Shammas JH, editor. Intraocular Lens Power Calculations: Slack Incorporated; 2004. p. 141-57.

12. Norrby S. Sources of error in intraocular lens power calculation. J Cataract Refract Surg. 2008 Mar;34(3):368-76.

13. Lee AC, Qazi MA, Pepose JS. Biometry and intraocular lens power calculation. Curr Opin Ophthalmol. 2008 Jan;19(1):13-7.

14. Olsen T CL, Gimbel H. Intraocular lens power calculation with an improved anterior chamber depth prediction algorithm. J Cataract Refract Surg. 1995;21(3):313-0.

15. Hoffer KJ. The Hoffer $Q$ formula: a comparison of theoretic and regression formulas. J Cataract Refract Surg. 1993 Nov;19(6):700-12.

16. Norrby S, Lydahl E, Koranyi G, Taube M. Reduction of trend errors in power calculation by linear transformation of measured axial lengths. J Cataract Refract Surg. 2003 Jan;29(1):100-5.

17. Holladay JT, Prager TC, Chandler TY, Musgrove KH, Lewis JW, Ruiz RS. A threepart system for refining intraocular lens power calculations. J Cataract Refract Surg. 1988 Jan;14(1):17-24.

18. Retzlaff JA, Sanders DR, Kraff MC. Development of the SRK/T intraocular lens implant power calculation formula. J Cataract Refract Surg. 1990 May;16(3):333-40.

19. Haigis W. Einflub der Optikform auf die individuelle Anpassung von Linsenkonstanten zur IOL-Berechnung. In: Rochels R, Duncker GIW, Hartmann CH, eds. 9. Kongress d Deutsch Ges f Intraokularlinsen Implant, Kiel 1995 Berlin: Springer- Berlag; 1996;183-189. 
20. Saeed A, Guerin M, Khan I, Keane P, Stack J, Hayes P, et al. Deferral of first review after uneventful phacoemulsification cataract surgery until 2 weeks: randomized controlled study. J Cataract Refract Surg. 2007 Sep;33(9):1591-6.

21. Tuft SJ, Manassian D. Paired observations of refractive error after cataract surgery. Ophthalmic Epidemiol. 2005 Apr;12(2):139-42.

22. Gale RP, Saha N, Johnston RL. National biometry audit. Eye. 2004 Jan;18(1):63-6.

23. Korynta J. [Importance of individualizing the formula for improving the accuracy of calculating emmetropia in intraocular lenses before cataract surgery]. Cesk Slov Oftalmol. 1995 Feb;51(1):45-50.

24. Hoffer KJ. Intraocular lens calculation: the problem of the short eye. Ophthalmic Surg. 1981 Apr;12(4):269-72.

25. Intraocular lens calculation: the problem of the short eye. Ophthalmic Surg. 1982 May;13(5):419-20.

26. Hoffer KJ. Lens power calculation and the problem of the short eye. Ophthalmic Surg. 1982 Nov;13(11):962.

\section{Legends to Figures}

Figure 1: Boxplot of the $A E$ derived using optimized Haigis lens constants and personalized Haigis lens constants in short, average and long eyes. $(A E=$ absolute error, opt = optimized Haigis lens constants, per = personalized Haigis lens constants).

Figure 2: Bland-Altman plots illustrating agreement between the AE after cataract surgery using optimized Haigis lens constants versus personalized Haigis lens constants. The solid horizontal line represents the mean difference between the AE using the two techniques, with the dotted lines representing the upper and lower limits of agreement, in all eyes $(A)$, short eyes $(B)$, average eyes $(C)$ and long eyes $(D)$. (Difference $=\mathrm{AE}$ using optimized lens constants minus $A E$ using personalized lens constants; Mean = mean value of the $A E$ using optimized lens constants and the $A E$ using personalized lens constants).

Figure 3: Cumulative percentage of operated eyes (y axis) that achieved less than or equal to a given error of prediction (x axis) using personalized (solid line) and optimized (dashed line) Haigis lens constants in all eyes $(A)$, in short eyes $(B)$, average eyes $(C)$ and long eyes $(D)$. 
Optimized versus Personalized Lens Constants

1

2

3

4

5

6

8

10

11

12

13

14

15

16

17

18

19

20

21

22

23

24

25

26

27

28

29

30

31

32

33

34

35

36

37

38

39

40

41

42

43

44

45

46

47

48

49

50

51

52

53

54

55

56

57

58

59

60

61

62

63

64

65 
Personalized Haigis lens constants showed marginal, but statistically non-significant, refractive advantages over optimized Haigis lens constants, in short eyes only, following phacoemulsification cataract surgery. 
Figure
Click here to download high resolution image

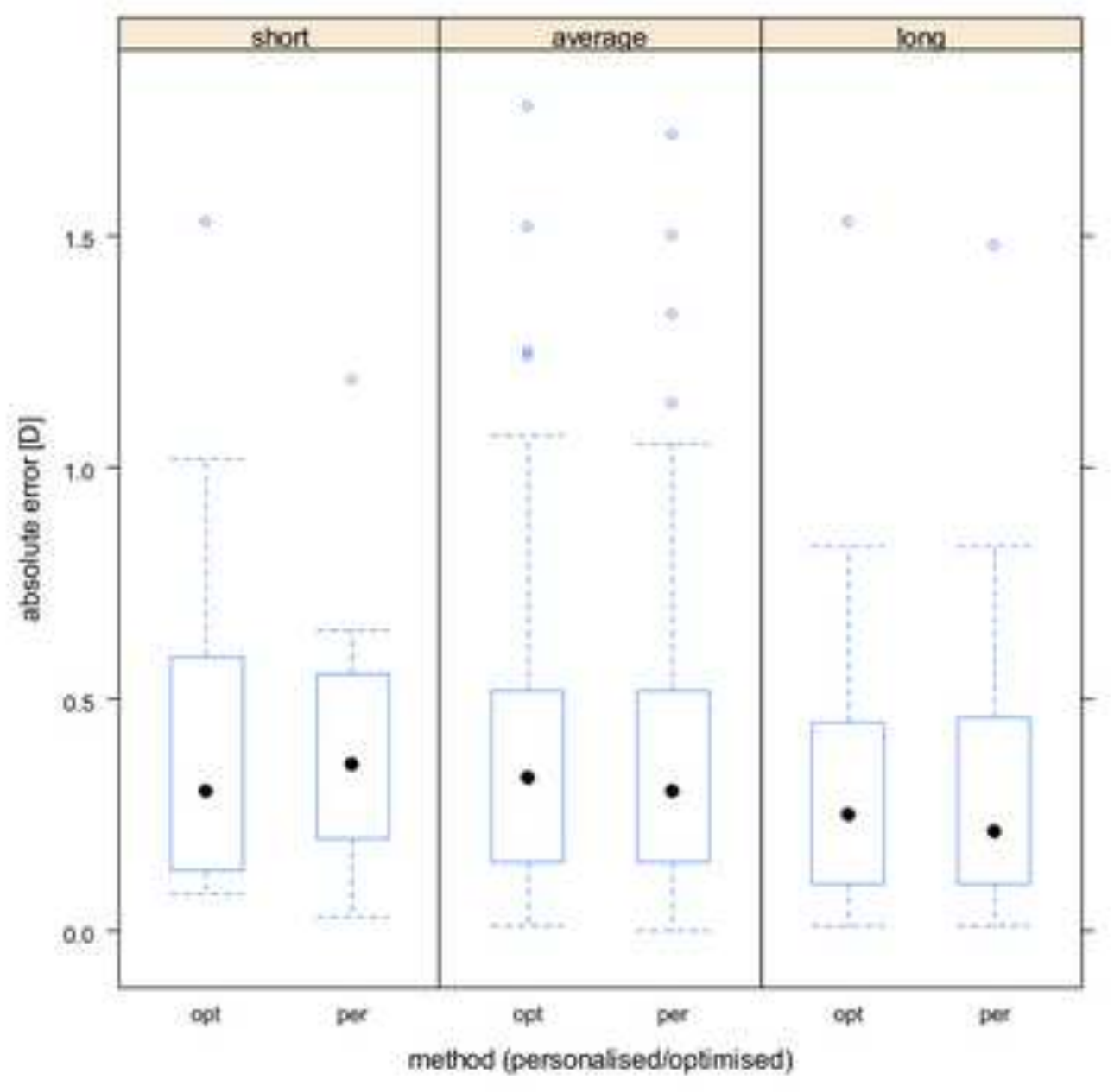

1 
Figure
Click here to download high resolution image

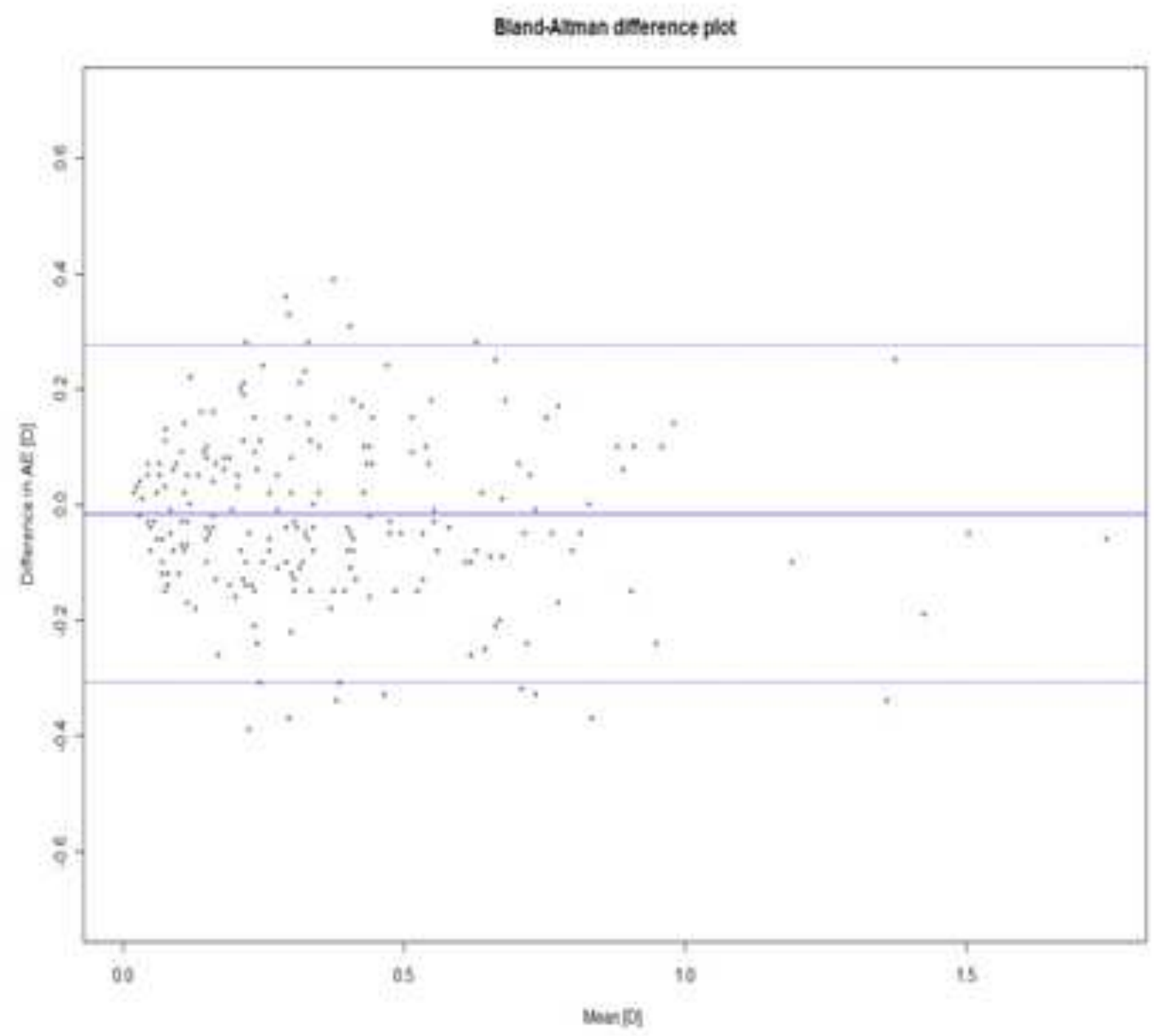

$2 A$

Mean difference $=-0.015(95 \% \mathrm{Cl} ;-0.035-0.004)$

Upper agreement limit $=0.277(95 \% \mathrm{Cl}: 0.243-0.312)$

Lower agreement limit $=-0.308(95 \% \mathrm{Cl}:-0.342--0.274)$ 
Click here to download high resolution image

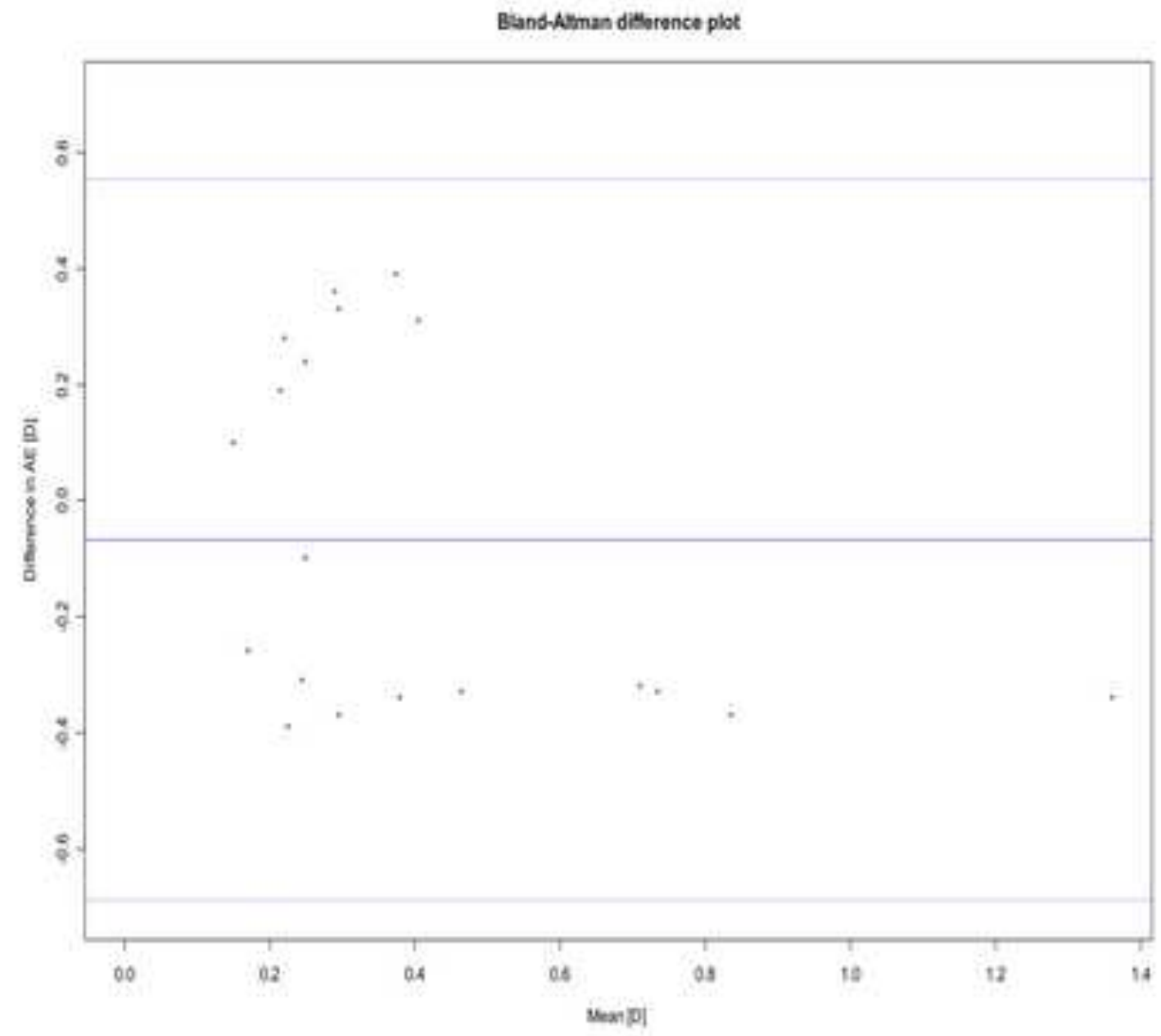

\section{$2 B$}

Mean difference $=-0.66(95 \% \mathrm{Cl}:-0.216-0.083)$

Upper agreement limit $=0.555(95 \% \mathrm{Cl}: 0.296-0.814)$

Lower agreement limit $=-0.687(95 \% \mathrm{Cl}:-0.947-0.428)$ 
Figure
Click here to download high resolution image

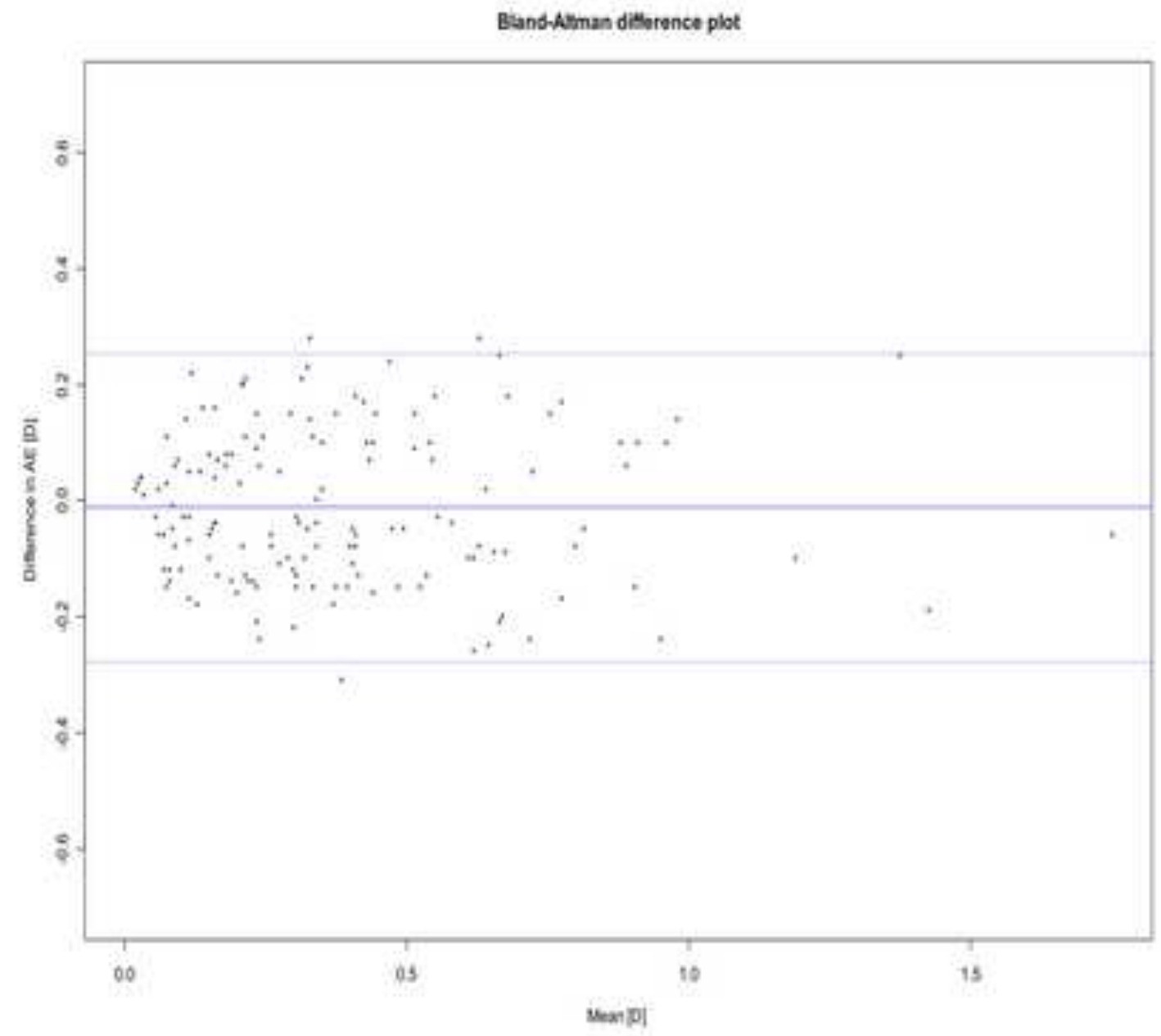

\section{$2 C$}

Mean difference $=-0.12(95 \% \mathrm{Cl}:-0.033-0.010)$

Upper agreement limit $=(95 \% \mathrm{Cl}: 0.217 \cdot 0.291)$

Lower agreement limit $=-0.277(95 \% \mathrm{Cl}:-0.315-0.240)$ 
Figure
Click here to download high resolution image

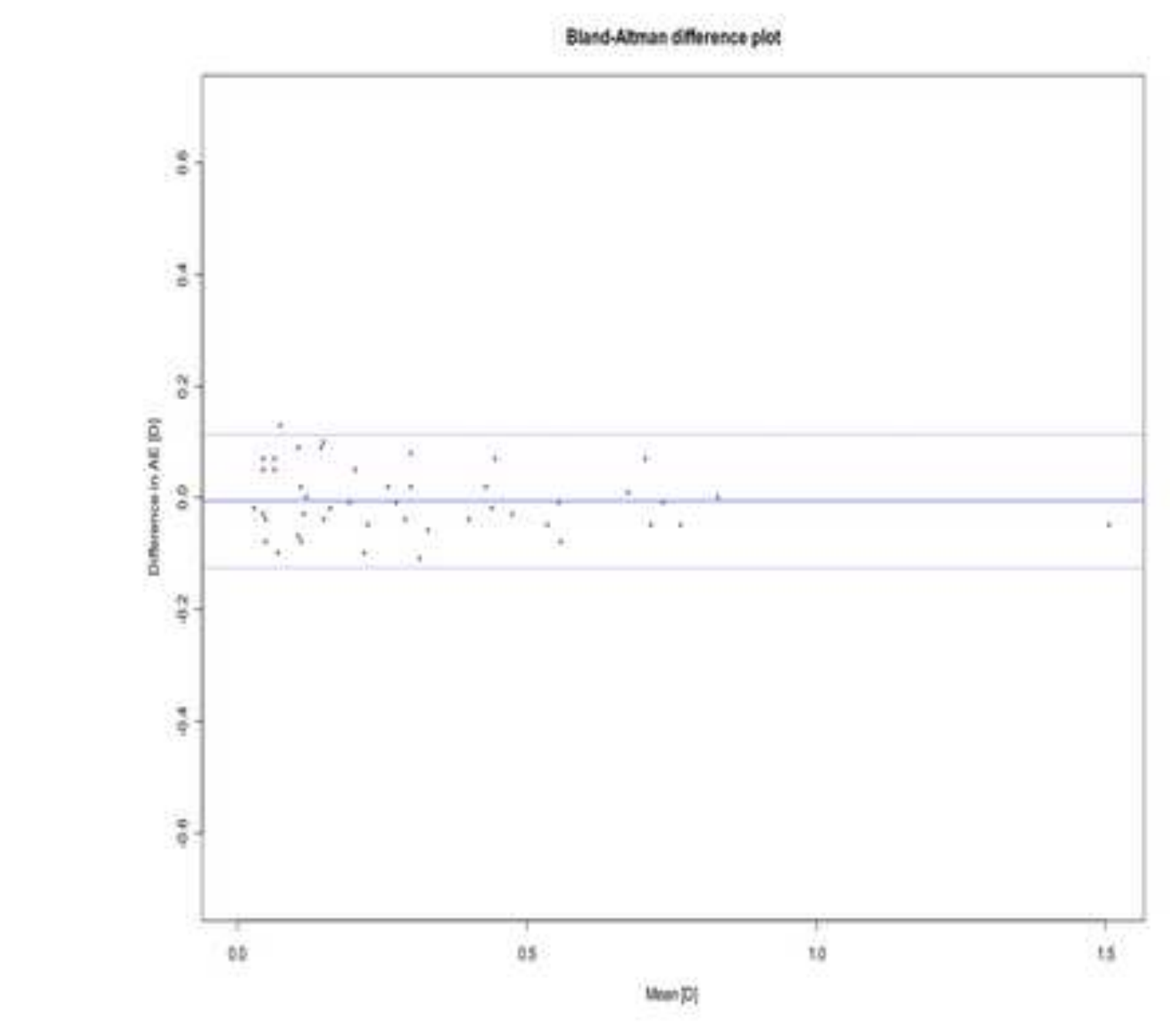

\begin{abstract}
$2 D$
Mean difference $=-0.006(95 \% \mathrm{Cl}:-0.024-0.012)$

Upper agreement limit $=0.113(95 \% \mathrm{Cl}: 0.083-0.144)$

Lower agreement limit $=-0.125(95 \% \mathrm{Cl} ;-0.156--0.094)$

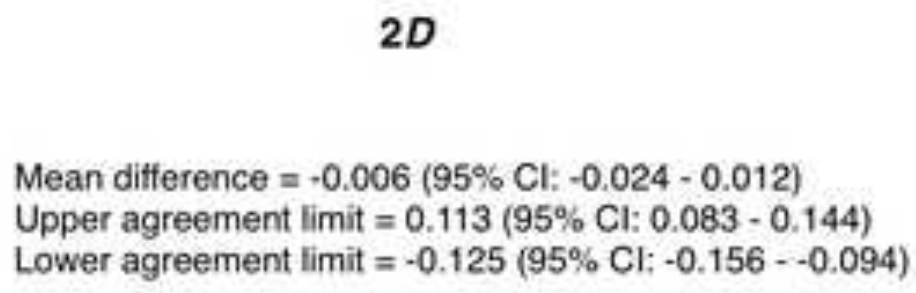

Lower agreement limit = $-0.125(95 \% \mathrm{Cl} ;-0.156-0.094)$
\end{abstract}

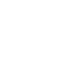


Figure

Figure $3 \mathrm{~A}$

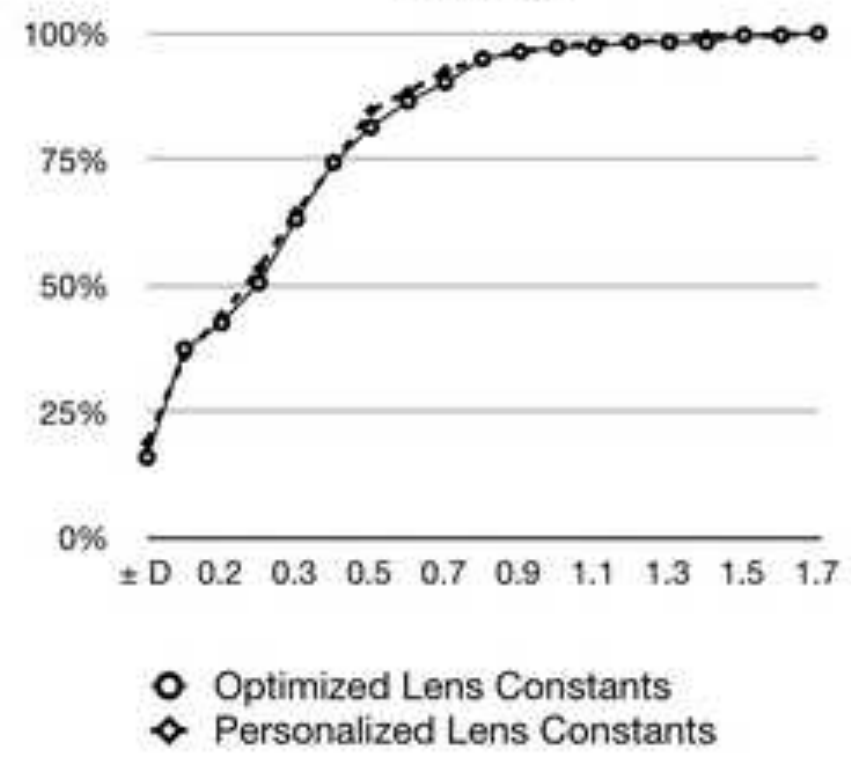

Click here to download high resolution image

$\diamond$ Personalized Lens Constants 
Figure

Figure 3B

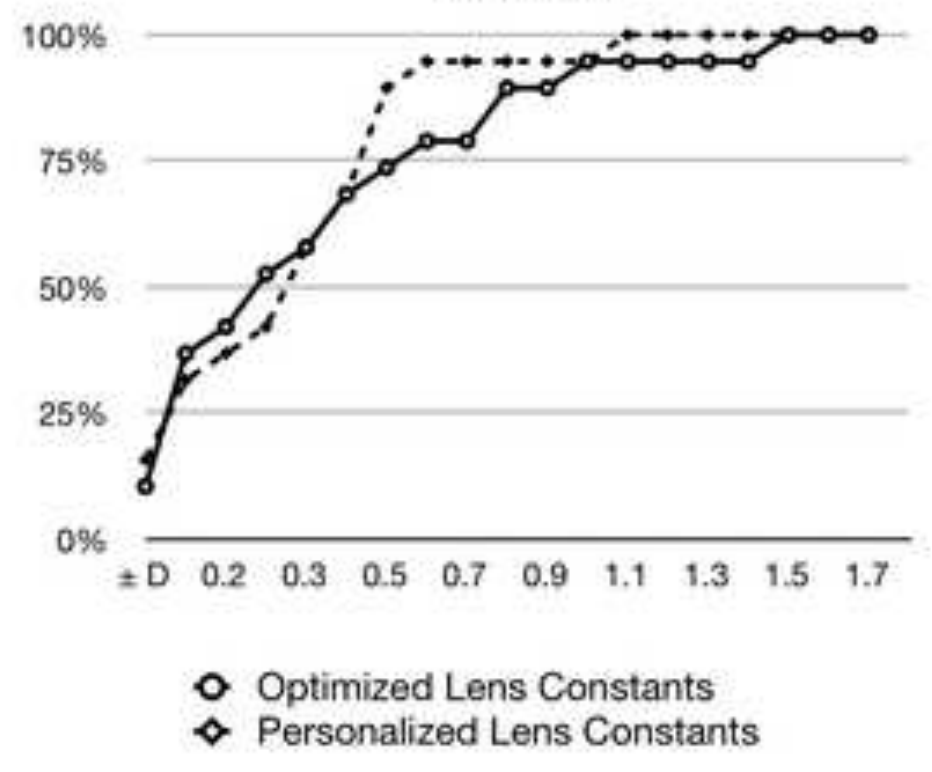

Click here to download high resolution image

$\diamond$ Personalized Lens Constants 
Figure

Figure $3 \mathrm{C}$

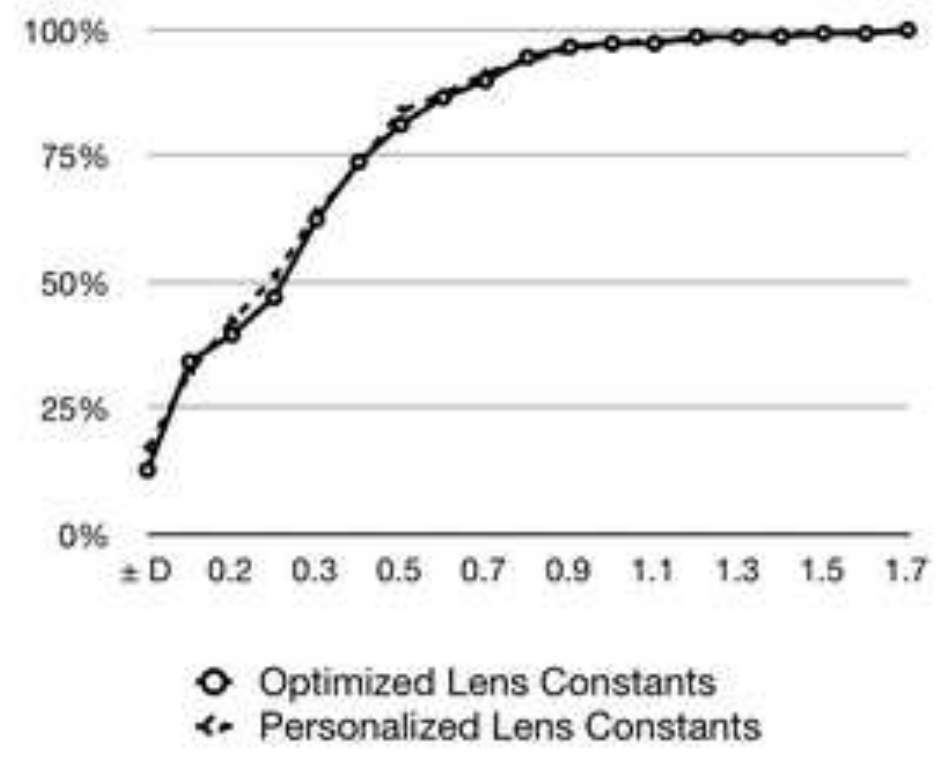

Click here to download high resolution image

«. Personalized Lens Constants 
Figure

Figure 3D

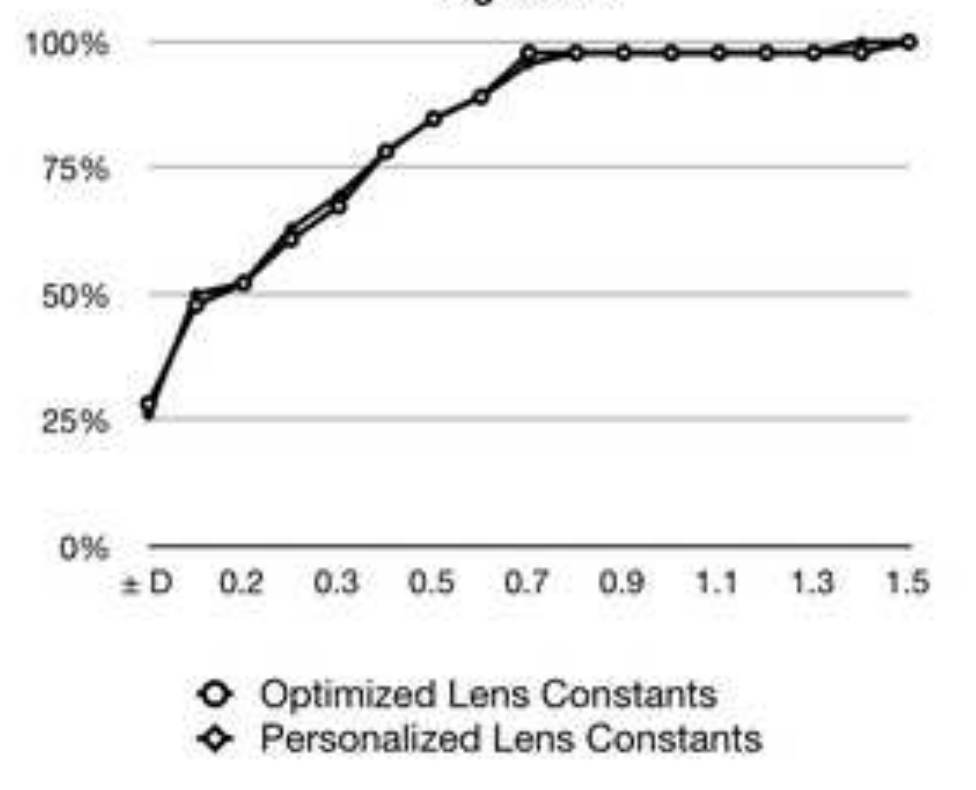

\section{Click here to download high resolution image}

$\diamond$ Personalized Lens Constants

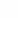


Table 1. Method of lens constant personalization employed by consultant ophthalmic surgeons in the UK and

\begin{tabular}{|c|c|}
\hline Method of personalization & Number of surgeons (\%) \\
\hline $\begin{array}{l}\text { Informal methods of lens constant adjustment, related to ones own } \\
\text { l experience }{ }^{\mathrm{a}}\end{array}$ & $75 / 198(37.9 \%)$ \\
\hline Electronic medical record system $\left(\text { Medisoft }{ }^{(B)}\right)^{a}$ & $55 / 198(27.8 \%)$ \\
\hline ULIB website $^{\mathrm{b}}$ /Warren Hill website ${ }^{\mathrm{c}}$ & $36 / 198(18.2 \%)$ \\
\hline IOLMaster ${ }^{(\otimes)}$ & $7 / 198(3.5 \%)$ \\
\hline Holladay IOL Consultant $\left.{ }^{(}\right)$ & $6 / 198(3 \%)$ \\
\hline Method not recognized by the authors ${ }^{d}$ & $3 / 198(1.5 \%)$ \\
\hline Hoffer $^{(\circledast)}$ Programs 1 LL Power Accuracy Software ${ }^{e}$ & $2 / 198(1 \%)$ \\
\hline Okulix $^{(\Theta)}$ program package ${ }^{\dagger}$ & $1 / 198(0.5 \%)$ \\
\hline Unknown/ not specified/ question left unanswered & $13 / 198(6.6 \%)$ \\
\hline
\end{tabular}

${ }^{\text {a}}$ Not explicitly specified whether data from a single surgeon or multiple surgeons were used; the term personalization should infer a process specific to the individual surgeon; the authors acknowledge that this represents a limitation of the questionnaire design.

bhttp://www.augenklinik.uni-wuerzburg.de/ulib/cl.htm.

http://doctor-hill.com/zeiss iolmaster/haigis formula.htm.

'Back/Bates proportional method, IOL brain neural net software, London vision clinic optimization.

ewww.eyelab.com.

| www.okulix.dehttp://okulix.de/index/htm. 
Table 2. Mean error (ME) of prediction numerical PE and mean absolute error (MAE)AE with Haigis optimized lens constants and with Haigis personalized lens constants, and percentage of eyes with an error of prediction numerical PE of $\pm 1.00 \mathrm{D}, \pm$ $0.50 D$ and $\pm 0.25 D$ in all eyes $(n=214)$, short eyes $(n=19)$, average eyes $(n=149)$ and long eyes $(n=46)$.

\begin{tabular}{|c|c|c|c|c|c|c|c|c|c|}
\hline \multicolumn{10}{|c|}{ All eyes $(n=214)$} \\
\hline \multicolumn{5}{|c|}{ Optimized Haigis Lens Constants } & \multicolumn{5}{|c|}{ Personalized Haigis Lens Constants } \\
\hline \multirow[b]{2}{*}{$\begin{array}{c}\text { ME of predictionMean } \\
\text { numerical PE (D) } \\
\text { (Range) }\end{array}$} & \multirow[b]{2}{*}{$\begin{array}{l}\text { Mean-AE } \\
\text { (D) (Range) }\end{array}$} & \multicolumn{3}{|c|}{ Eyes (\%) } & \multirow[b]{2}{*}{$\begin{array}{l}\text { ME of prediction } \\
\text { Mean numerical } \\
\text { PE (D) (Range) }\end{array}$} & \multirow[b]{2}{*}{$\begin{array}{l}\text { Mean AE } \\
\text { (D) (Range) }\end{array}$} & \multicolumn{3}{|c|}{ Eyes (\%) } \\
\hline & & $\begin{array}{c} \pm \\
1.00 \\
D\end{array}$ & $\begin{array}{l} \pm \\
0.50 \\
D\end{array}$ & $\begin{array}{c} \pm \\
0.25 \\
D\end{array}$ & & & $\begin{array}{c} \pm \\
1.00 \\
D\end{array}$ & $\begin{array}{c} \pm \\
0.50 \\
D\end{array}$ & $\begin{array}{l} \pm \\
0.25 \\
D\end{array}$ \\
\hline $\begin{array}{c}-0.09 \mathrm{D} \pm 0.48 \\
(-1.78 \text { to }+1.53)\end{array}$ & $\begin{array}{c}0.38 \pm 0.31^{*} \\
(0.01 \text { to } 1.78)\end{array}$ & $96^{\star \star}$ & $74^{\star *}$ & $43^{* *}$ & $\begin{array}{l}+0.01 \mathrm{D} \pm 0.47 \\
(-1.72 \text { to }+1.50)\end{array}$ & $\begin{array}{r}0.36 \\
(0.00\end{array}$ & $96^{* *}$ & $73^{\star *}$ & $44^{\star \star}$ \\
\hline \multicolumn{10}{|c|}{ Short eyes $(n=19)$} \\
\hline \multicolumn{5}{|c|}{ Optimized Haigis Lens Constants } & \multicolumn{5}{|c|}{ Personalized Haigis Lens Constants } \\
\hline & & \multicolumn{3}{|c|}{ Eyes (\%) } & & & \multicolumn{3}{|c|}{ Eyes (\%) } \\
\hline 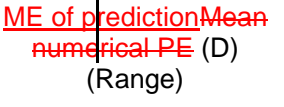 & $\begin{array}{l}\text { Mean AE } \\
\text { (D) (Range) }\end{array}$ & $\begin{array}{c} \pm \\
1.00 \\
D\end{array}$ & $\begin{array}{l} \pm \\
0.50 \\
D\end{array}$ & $\begin{array}{c} \pm \\
0.25 \\
D\end{array}$ & $\begin{array}{l}\text { ME of prediction } \\
\text { Mean numerical } \\
\text { PE (D) (Range) }\end{array}$ & $\begin{array}{l}\text { Mean AE } \\
\text { (D) (Range) }\end{array}$ & $\begin{array}{c} \pm \\
1.00 \\
D\end{array}$ & $\begin{array}{l} \pm \\
0.50 \\
D\end{array}$ & $\begin{array}{c} \pm \\
0.25 \\
D\end{array}$ \\
\hline $\begin{array}{c}-0.37 \pm 0.47 \\
(-1.53 \text { to }+0.25)\end{array}$ & $\begin{array}{c}0.45 \pm 0.39^{*} \\
(0.10 \text { to } 1.53)\end{array}$ & $89^{* *}$ & $68^{\star *}$ & $42^{* *}$ & $\begin{array}{c}-0.01 \pm 0.48 \\
(-1.19 \text { to }+0.57)\end{array}$ & $\begin{array}{c}0.38 \pm 0.28^{*} \\
(0.03 \text { to } 1.19)\end{array}$ & $95^{\star \star}$ & $68^{* *}$ & $37^{\star *}$ \\
\hline \multicolumn{10}{|c|}{ Average eyes $(n=149)$} \\
\hline \multicolumn{5}{|c|}{ Optimized Haigis Lens Constants } & \multicolumn{5}{|c|}{ Personalized Haigis Lens Constants } \\
\hline & & \multicolumn{3}{|c|}{ Eyes (\%) } & & & \multicolumn{3}{|c|}{ Eyes (\%) } \\
\hline $\begin{array}{c}\text { ME of predictionAlean } \\
\text { numerical PE (D) } \\
\text { (Range) }\end{array}$ & $\begin{array}{l}\text { Mean-AE } \\
\text { (D) (Range) }\end{array}$ & $\begin{array}{c} \pm \\
1.00 \\
D\end{array}$ & $\begin{array}{c} \pm \\
0.50 \\
D\end{array}$ & $\begin{array}{c} \pm \\
0.25 \\
D\end{array}$ & $\begin{array}{l}\text { ME of prediction } \\
\text { Mean numerical } \\
\text { PE (D) (Range) }\end{array}$ & $\begin{array}{l}\text { Mean-AE } \\
\text { (D) (Range) }\end{array}$ & $\begin{array}{c} \pm \\
1.00 \\
D\end{array}$ & $\begin{array}{c} \pm \\
0.50 \\
D\end{array}$ & $\begin{array}{l} \pm \\
0.25 \\
D\end{array}$ \\
\hline $\begin{array}{c}-0.11 \pm 0.48 \\
(-1.78 \text { to }+1.25)\end{array}$ & $\begin{array}{l}0.38 \pm 0.31^{*} \\
(0 \text { to } 1.78)\end{array}$ & $97^{\star *}$ & $74^{\star \star}$ & $40^{* *}$ & $\begin{array}{c}+0.02 \pm 0.46 \\
(-1.72 \text { to }+1.50)\end{array}$ & $\begin{array}{l}0.37 \pm 0.30^{*} \\
(0 \text { to } 1.72)\end{array}$ & $96^{\star \star}$ & $73^{\star \star}$ & $42^{\star \star}$ \\
\hline \multicolumn{10}{|c|}{ Long eyes $(n=46)$} \\
\hline \multicolumn{5}{|c|}{ Optimized Haigis Lens Constants } & \multicolumn{5}{|c|}{ Personalized Haigis Lens Constants } \\
\hline & & \multicolumn{3}{|c|}{ Eyes (\%) } & & & \multicolumn{3}{|c|}{ Eyes (\%) } \\
\hline $\begin{array}{c}\frac{\text { ME of predictionMean }}{\text { numerical PE (D) }} \\
\text { (Range) }\end{array}$ & $\begin{array}{l}\text { Mean-AE } \\
\text { (D) (Range) }\end{array}$ & $\begin{array}{c} \pm \\
1.00 \\
D\end{array}$ & $\begin{array}{l} \pm \\
0.50 \\
D\end{array}$ & $\begin{array}{c} \pm \\
0.25 \\
D\end{array}$ & $\begin{array}{l}\frac{\text { ME of prediction }}{\text { Mean numerical }} \\
\text { PE (D) (Range) }\end{array}$ & $\begin{array}{l}\text { Mean } A E \\
\text { (D) (Range) }\end{array}$ & $\begin{array}{c} \pm \\
1.00 \\
D\end{array}$ & $\begin{array}{l} \pm \\
0.50 \\
D\end{array}$ & $\begin{array}{c} \pm \\
0.25 \\
D\end{array}$ \\
\hline $\begin{array}{c}+0.08 \pm 0.43 \\
(-0.83 \text { to }+1.53)\end{array}$ & $\begin{array}{c}0.32 \pm 0.30^{*} \\
(0.01 \text { to } 1.53)\end{array}$ & $98^{\star *}$ & $78^{\star *}$ & $52^{\star \star}$ & $\begin{array}{c}+0.05 \pm 0.41 \\
(-0.83 \text { to }+1.48)\end{array}$ & $\begin{array}{l}0.32 \pm 0.29^{*} \\
(0 \text { to } 1.48)\end{array}$ & $98^{\star *}$ & $78^{\star \star}$ & $52^{\star \star}$ \\
\hline
\end{tabular}
Mean $+/-$ SD

MPE $=$ mean prediction error

$\underline{M} A E=\underline{\text { mean }}$ absolute error

$*$ p-value $>0.05$ (paired t-test comparing corresponding outcome measures for optimized and personalized lens constants) 
** $\mathrm{p}$-value > 0.05 (McNemar's comparing corresponding outcome measures for optimized and personalized lens constants) 
Click here to download high resolution image

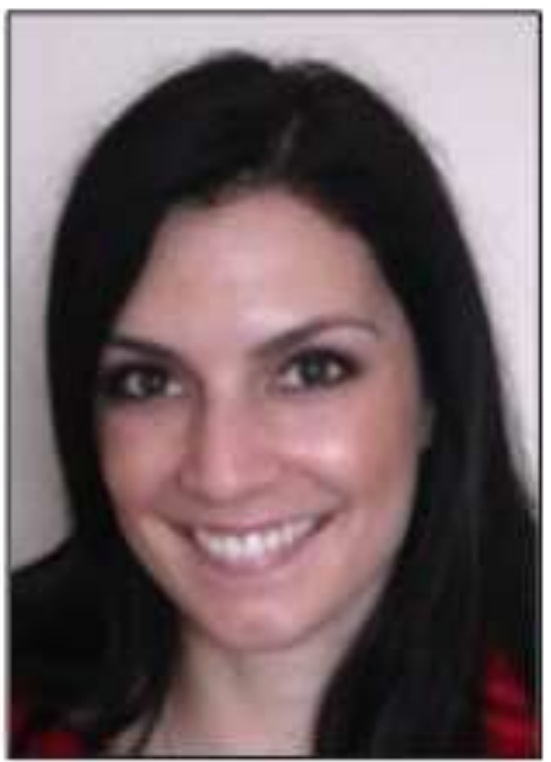

